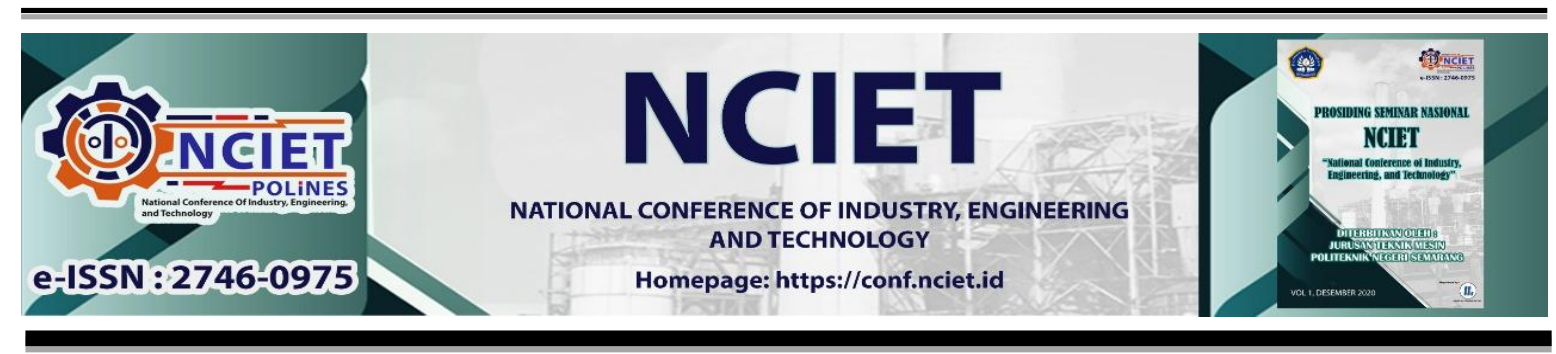

Prosiding Seminar Nasional NCIET Vol.1 (2020) B286-B292

$1^{\text {st }}$ National Conference of Industry, Engineering and Technology 2020,

Semarang, Indonesia.

\title{
KARAKTERISTIK LOGIC IR2103 PADA MOTOR BLDC UNTUK APLIKASI SEPEDA LISTRIK
}

\author{
Qoriatul Fitriyah $^{1 *}$, Renaldy Aritha ${ }^{1}$, Berto Yusuf Nugroho ${ }^{2}$, M. Prihadi Eko W ${ }^{1}$ \\ ${ }^{1}$ Jurusan Teknik Elektro, Politeknik Negeri Batam \\ Jl. Ahmad Yani Batam Kota. Kota Batam. Kepulauan Riau, 29461 \\ ${ }^{2}$ Pemeliharaan Kendaraan Ringan, Akademi Komunitas Negeri Pacitan \\ JL. Walanda Maramis 04A Kab. Pacitan, 63514 \\ *E-mail: fitriyah@polibatam.ac.id
}

\begin{abstract}
Abstrak
Pengujian mosfet driver IR2103 pada motor BLDC merupakan salah satu komponen penting dalam aplikasi sepeda listrik. Pengujian dilakukan pada beberapa tempat, termasuk pada inverter dan converter. Pada inverter, pengujian ini dilakukan dengan mengambil sinyal dari salah satu IR2103 dalam membangkitkan fasa yang menuju motor BLDC. Hasil pengujian ini digunakan salah satunya dalam penentuan parameter safety agar tidak terjadi short antara Mosfet High Side dan Mosfet Low Side pada inverter.
\end{abstract}

Kata Kunci: Motor BLDC; Sepeda Listrik; IR2103; mosfet driver IR2103; inverter, converter

\section{PENDAHULUAN}

\section{Sepeda Listrik}

Secara umum, sepeda listrik dirancang untuk mengatasi masalah polusi dengan tidak melupakan aspek ekonomis $[1,2]$.

Sepada listrik bisa menjadi solusi di masa depan dengan karakteristik stabilitas yang berkelanjutan. Sepada ini dioperasikan dengan menggunakan baterai yang rendah biaya perawatan maupun emisi (polusi) yang dihasilkan. Sepeda listrik merupakan alat transportasi pengganti yang menarik baik bagi sepeda konvensional maupun kendaraan pribadi bermotor. Kelebihannya adalah ramah lingkungan, efisien, serta aman dan nyaman untuk dipakai [1-3].

Sebuah sepeda listrik akan terdiri dari beberapa komponen, yaitu: 


\section{Motor DC}



Gambar 1. Ilustrasi Winding Motor BLDC [4]

Motor yang digunakan merupakan jenis motor BLDC dengan beberapa keuntungan [5]:

1. Dimensi motor lebih kecil daripada motor DC konvensional

2. Efisiensi lebih besar daripada motor induksi

3. Dengan ketiadaan sikat, perawatan menjadi lebih ringan

4. Hampir tidak ada noise

5. Respon motor lebih cepat

6. Umur pemakaian lebih lama

7. Rentang kecepatan lebih lebar

\section{Baterai}

Jenis baterai yang digunakan merupakan baterai lithium yang bisa diisi ulang. Baterai ini digunakan di banyak jenis kendaraan elektrik karena efisiensinya. Baterai ini ringan, memiliki kecepatan yang tinggi, tidak menghasilkan polusi serta lebih bisa diandalkan dibandingkan jenis baterai yang lain [1-3]. 


\section{Frame}

Frame atau kerangka merupakan struktur inti dari sepeda listrik yang digunakan untuk tempat menyangga motor BLDC, menyiapkan dasar bagi semua komponen juga bagi penumpang sepeda. Baterai juga ditempelkan pada bagian frame [1-3].

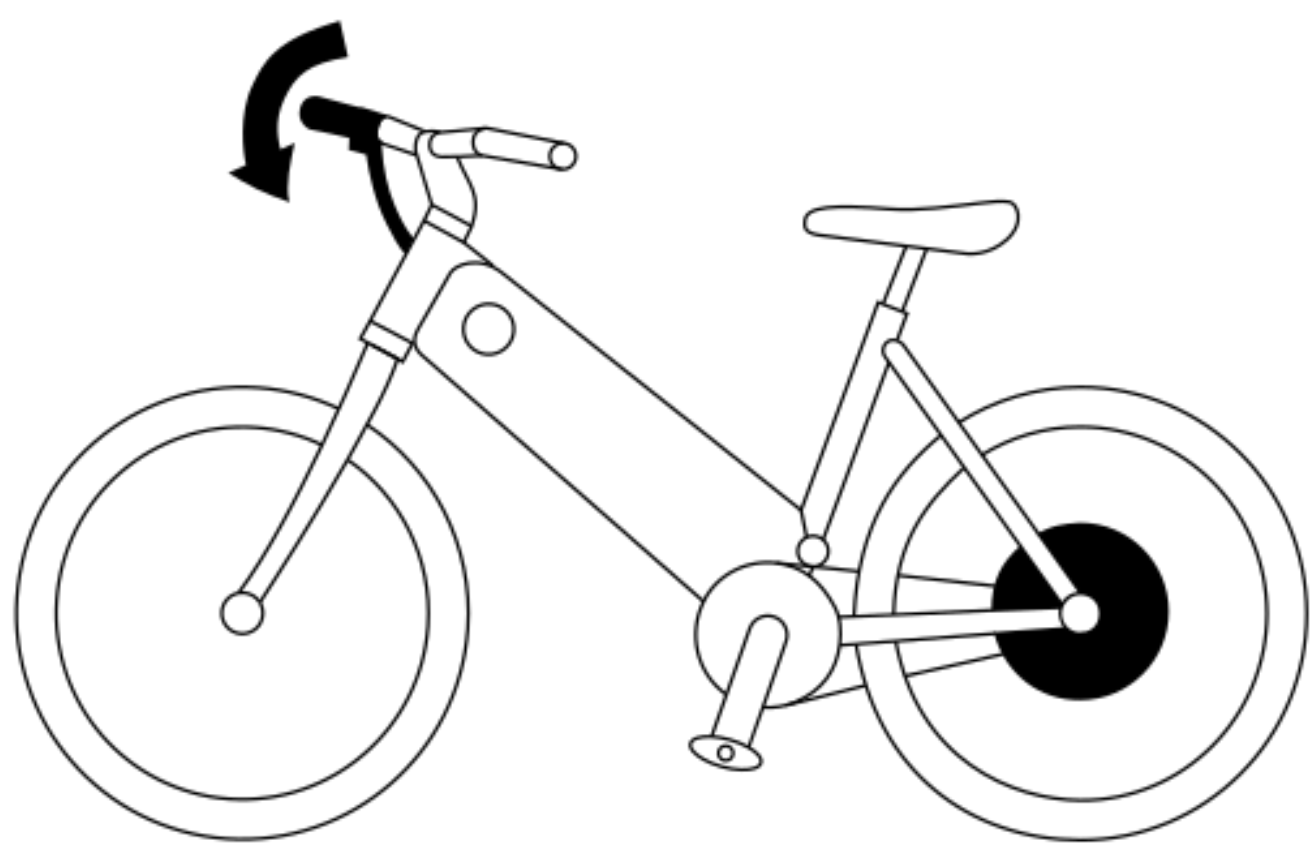

Gambar 2. Contoh Frame pada Sepeda Listrik [6]

\section{Sistem Pengereman}

Sistem pengereman pada sepeda listrik menggunakan prinsip perubahan energi kinetik menjadi energi termal melalui gesekan. Breaking dilakukan dengan model band brake system $[1,2]$.

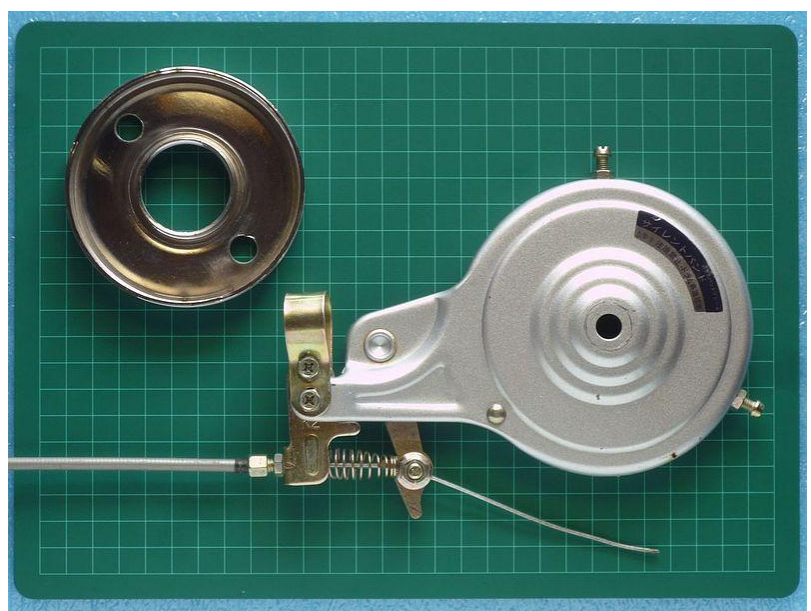

Gambar 3. Band Brake System pada Sepeda Listrik [7] 


\section{Sistem Transmisi}

Sistem transmisi menggunakan model rantai untuk daya mekanik agar diperoleh putaran yang halus dari satu gear ke gear yang lain [1].

\section{METODE PENELITIAN}

Paper ini difokuskan pada karakteristik IR2103 pada motor BLDC yang digunakan hanya pada penggerak depan sepeda listrik. Berikut ini adalah rancangan perangkat keras yang telah dilakukan:

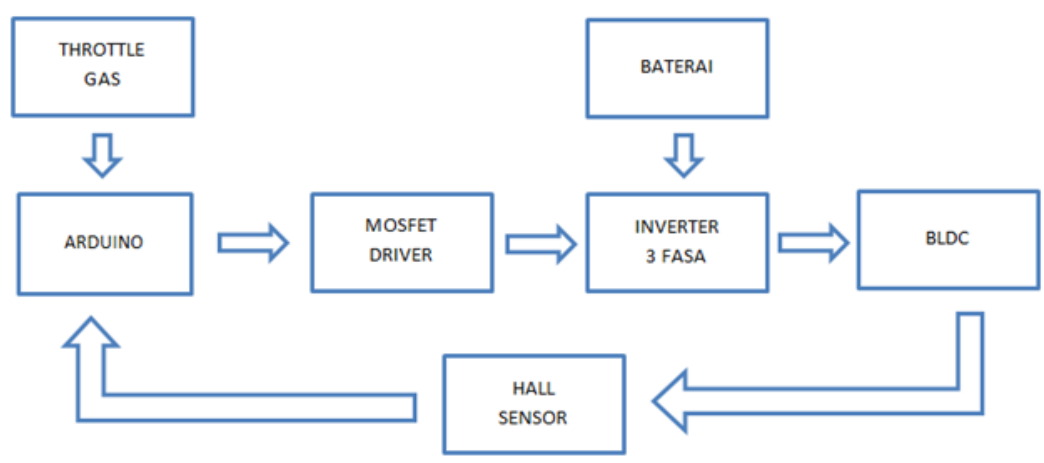

Gambar 4. Sistem Kerja Perangkat Keras Penggerak Depan pada Sepeda Listrik

Throttle gas digunakan sebagai input pada Arduino yang akan mengontrol pergerakan mosfet driver. Mosfet driver bergerak sebagai input dari inverter 3 fasa dengan bantuan baterai lithium. Inverter inilah yang mengatur masukan daya pada motor BLDC. Data dari motor BLDC dikirim kembali ke Arduino dengan bantuan hall sensor.

Agar motor brushless berputar dibutuhkan 6 kondisi pensaklaran dari inverter. Proses pensaklaran, sebagai berikut:



Gambar 5. Pensaklaran Step 1

Pada step 1, saat kondisi hall sensor bernilai 100 maka S1 dan S6 akan aktif. Arus positif mengalir melalui S1 menuju koil U dan keluar dari koil W melalui S6 menuju arus negatif. Motor akan berputar 60 derajat searah jarum jam. 


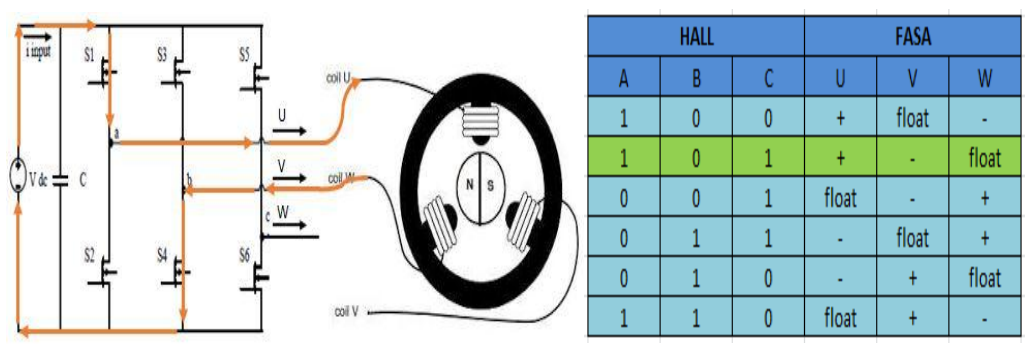

Gambar 6. Pensaklaran Step 2

Pada step 2, saat kondisi hall sensor bernilai 101 maka S1 dan S4 akan aktif. Arus positif mengalir melalui S1 menuju koil U dan keluar dari koil V melalui S4 menuju arus negatif. Motor berputar 60 derajat lagi searah jarum jam.
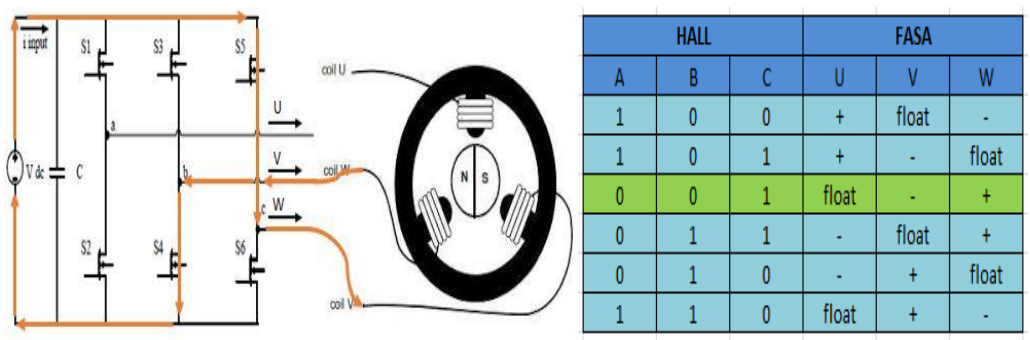

Gambar 7. Pensaklaran Step 3

Pada step 3, saat kondisi hall sensor bernilai 001 maka S5 dan S4 akan aktif. Arus positif mengalir melalui S5 menuju koil $\mathrm{W}$ dan keluar dari koil V melalui S4 menuju arus negatif. Motor berputar 60 derajat lagi searah jarum jam.

\section{HASIL DAN PEMBAHASAN}

Adapun tujuan dari pengujian alat untuk mengetahui pembuatan alat berjalan dengan baik. Pengujian yang dilakukan adalah mengukur kecepatan rpm motor dengan konsumsi daya motor ketika kecepatan berubah - ubah.

\section{Pengujian Mosfet Driver IR2103}

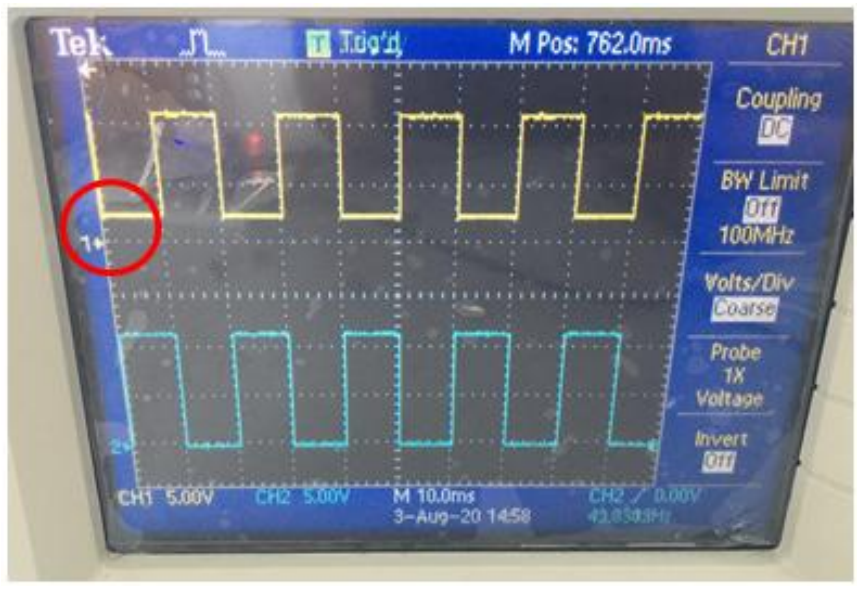

Gambar 8. Logic IR2103 dengan Kapasitor 
Gambar 8 merupakan pengujian sinyal High Side dan Low Side dari IR2103 menggunakan kapasitor 10uF. Channel 1 merupakan sinyal High Side dan channel 2 merupakan sinyal Low Side. Pada channel 1 terlihat sinyal rising dan falling tidak pada kondisi 0 volt, hal ini disebabkan karena penggunaan kapasitor $10 \mathrm{uF}$ pada pin VB dan VS di IR2103. Pin VB dan VS ini merupakan tegangan charging dan discharging untuk sinyal High Side.

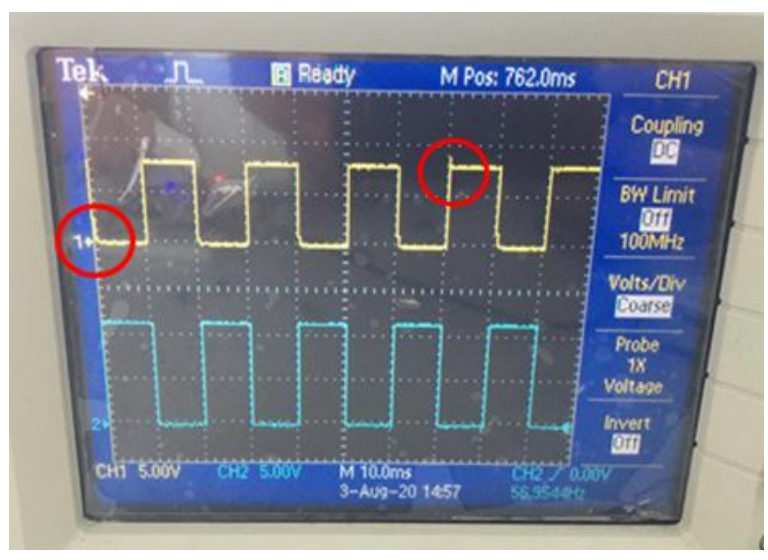

Gambar 9. Logic IR2103 tanpa Kapasitor

Gambar 9 menjelaskan pengujian sinyal High Side dan Low Side tanpa kapasitor. Channel 1 merupakan sinyal High Side dan channel 2 merupakan sinyal Low Side. Pada channel 1 dapat dilihat kondisi rising dan falling sinyal High Side tepat pada 0 volt namun terdapat noise pada sinyal rising. Hal ini disebabkan karena tidak menggunakan kapasitor pada pin VB dan VS.

\section{Pengujian Sinyal IR2103 Terhadap Inverter}

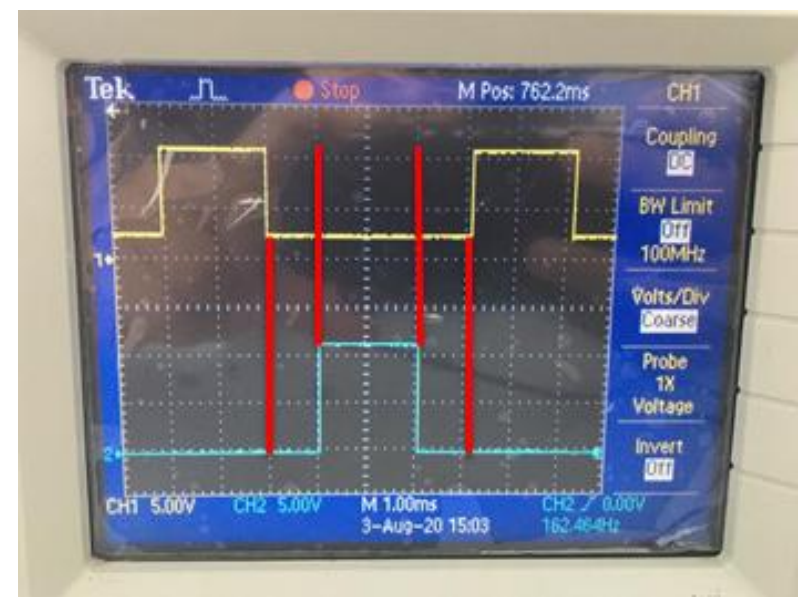

Gambar 10. Logic IR2103 Terhadap Inverter

Gambar 10 merupakan pengujian sinyal IR2103 terhadap inverter. Pengujian ini mengambil sinyal dari salah satu IR2103 dalam membangkitkan fasa yang menuju motor BLDC. Channel 1 merupakan sinyal High Side dan channel 2 merupakan sinyal Low Side. 
Ketika sinyal High Side aktif ada jeda waktu selama 1ms dengan sinyal Low Side ketika non aktif. Hal ini bertujuan agar tidak terjadi short antara Mosfet High Side dan Mosfet Low Side pada Inverter.

\section{KESIMPULAN}

Dalam pengujian IR2103 dengan kapasitor dapat dilihat kondisi rising dan falling pada sinyal High Side tidak tepat pada 0 volt, namun ini tidak masalah dikarenakan dengan tegangan sisa dari proses discharge dan charge yang dilakukan kapasitor pada pin VB dan VS sangat kecil dan ini tidak dapat membuat kondisi High Side aktif sehingga High Side dan Low Side tidak aktif dalam waktu bersamaan yang dapat membahayakan short circuit pada inverter. Namun pengujian IR2103 tanpa kapasitor kondisi rising dan falling sinyal High Side tepat pada 0 volt, tetapi ini tidak dianjurkan dikarenakan proses charge dan discharge inilah yang dilakukan kapasitor tersebut..

\section{DAFTAR PUSTAKA}

Sunikshita Katoch, R., Ranjit Kumar Bindal, Design and Implementation of Smart Electric Bike Eco-Friendly. International Journal of Innovative Technology and Exploring Engineering (IJITEE), 2019. 8(6S4).

Putra, G.S., PERANCANGAN KONTROL KECEPATAN MOTOR ARUS SEARAH TANPA SIKAT MENGGUNAKAN SLIDING MODE BERBASIS PID. 2016, Institut Teknologi Sepuluh Nopember.

Nanda Redha Arsya, H.S., dan Sjamsjul Anam, Desain Kontrol Kecepatan Motor Brushless DC Berbasis Power Factor Correction (PFC) Menggunakan Single Ended Primary Inductance Converter (SEPIC). JURNAL TEKNIK ITS, 2016. 5(2): p. 23373539.

Medvedev, Stator winding of a Brushless DC electric motor, in https://upload.wikimedia.org/wikipedia/commons/thumb/O/Of/Stator_Winding_of a_BL DC_Motor.jpg/720px-Stator_Winding_of_a_BLDC_Motor.jpg. 2013.

Agung Dwi Yulianta, S.P.H., Suharyanto, Pengendalian Kecepatan Motor Brushless DC (BLDC) menggunakan Metode Logika Fuzzy. Jurnal Sains, Teknologi dan Industri, 2015. 12: p. 248-254.

Haller, N., Illustration/Schema eines E-Bike, in https://upload.wikimedia.org/wikipedia/commons/thumb/9/9b/Schematic_of_an_EBike.svg/531px-Schematic_of_an_E-Bike.svg.png. 2009.

imoni，日本語：自転車後輪用ブレーキ バンドブレーキ表面，in https://upload.wikimedia.org/wikipedia/commons/thumb/5/57/Bandbrake \%28for bicycle rear wheel\%29a.jpg/800px-Bandbrake \%28for bicycle rear_wheel\%29a.jpg. 2010. 